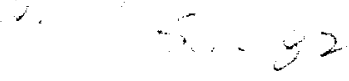 \\ N $90-28449$
}

\section{Communications and Media Services}

\author{
JAMES W. MCCULLA \\ JAMES F. KUKOWSKI*
}

By virtue of the National Aeronautics and Space Act (1958), the National Aeronautics and Space Administration (NASA) is required to be open about its activities and to maximize communication with the public. The Office of Communications is responsible for a wide variety of programs to meet these requirements: issuing press releases in both paper and electronic forms, serving the television and other media with audiovisual products, responding to public inquiries, coordinating speakers and exhibits, and assuring compliance with the Freedom of Information Act.

These programs have been extraordinarily well developed throughout the years of NASA successes in aeronautical research and development, manned missions, Earth observations, and space exploration. The programs are divided into two broad areas of public affairs: media services and public services. Traditionally, NASA relies heavily on the capabilities of television, newspapers, and periodicals to disseminate information to the public. While these avenues of communication have been highly effective since 1959 , service to the public via the media needs to be supplemented with direct communication in ways that only a NASA civil servant or contractor can manage (answering 25,000 pieces of correspondence annually, for example).

NASA boasts a significant internal communication program that dates from the agency's origin. It includes, of course, the communication of scientific and technical information that is inherent in its research and development missions, and, in an effort to go beyond the usual informal mechanisms and the obligatory administrative directives, it also includes a system of newsletters and employee briefings. These activities exist at both NASA-wide and installation levels. In addition to covering administrative matters and the general concerns of NASA personnel, the system includes occasional status reports on the

"Direct all correspondence to: James F. Kukowski, NASA Office of Communications, Code LPC, Washington, D.C. 20546-0001.

Government Information Quarterly, Volume 7, Number 2, pages 211-218. ISSN: 0740-624X. 
accomplishments and plans associated with NASA's ever-evolving scientific and technical missions.

NASA's internal and external communication methods are summarized in the paragraphs that follow. The Appendix of this issue contains a listing of sources that may be called upon to obtain these services.

\section{EXTERNAL COMMUNICATION}

\section{Information Services for the Media}

\section{Electronic Information Distribution}

NASA news releases and other information, including Space Shuttle status reports, Shuttle manifests, current mission information, public affairs contacts, and a calendar of events, are available electronically through Dialcom.

\section{NASA Select TVAudio System}

The NASA-wide TV-audio release system is a valuable tool for media covering the agency's activities. During Space Shuttle missions, the system provides real-time air-to- ground communications between the orbiter and mission control; public affairs launch, mission, and landing commentary; and many related news briefings. The system is also used for other NASA briefings and events. For most press briefings, the system is interactive (one-way video, two-way audio) among NASA installations so that media covering an event from one installation may ask questions at a briefing originating at another.

\section{Television}

NASA Headquarters produces a $14 \frac{1}{2}$-minute magazine-format videotape each quarter, called "Aeronautics and Space Report." The program is available to TV stations via satellite through the services of Medialink. It is also uplinked to NASA installations via the NASA Select TV system. As an aid to broadcasters wishing to excerpt portions of this videotape for news programming, both audio channels are used. Channel 1 audio carries a completely mixed track with narration, music, actualities, and effects. Channel 2 audio has effects and actualities only.

Audio

NASA produces a weekly 41/2-minute program called "The Space Story" and a 90-second spot called "Frontiers." These topical radio programs feature astronauts, scientists, and other people involved in NASA's ongoing research efforts. These programs are distributed via satellite and on broadcast-quality cassettes to thousands of radio stations in the United States and abroad. Audio tapes of mission highlights and other space-age sound effects are also available from the NASA radio office.

\section{NASA Broadcast News Service}

Several NASA installations also provide up-to-date reports on aeronautics and space activities through automated telephone systems. Status reports during Space Shuttle missions 
are available from the John F. Kennedy Space Center (prelaunch information), Lyndon B. Johnson Space Center (mission operations), and Dryden Flight Research Facility (landing operations). The Headquarters audio news service makes it possible for stations to receive material from interviews with the astronauts before Space Shuttle missions.

\section{Motion Pictures}

Films describing NASA research and development programs in space and aeronautics may be borrowed from one of seven regional film libraries. There is no charge, but'borrowers must pay the cost of return postage and insurance. Regional film libraries are maintained at all NASA installations.

\section{Still Photography}

NASA installations maintain photo files on current projects and those of the recent past. Older files are purged periodically to make room for new material. The Broadcast and Audio Visual Branch, NASA Headquarters, has files covering projects and missions extending back to the agency's creation in 1958. Researchers seeking early or general material may save time by beginning their search at Headquarters.

\section{Information Services for the Public}

\section{Astronaut Appearances}

NASA responds to requests for astronaut appearances, both foreign and domestic. In 1988, NASA astronauts made 1,525 individual appearances in the United States and 435 in foreign countries. NASA also supports postflight appearances of individual astronauts and Space Shuttle mission crews.

\section{Exhibits}

The best of NASA technology is represented through the planning, design, and implementation of major NASA exhibits to be featured at expositions and air shows across the United States and in foreign countries. In addition to these exhibits, NASA maintains an overall exhibits program, supporting the requirements for Headquarters program office and installations.

\section{Graphic Arts}

To assure the standardized use of graphic designs throughout NASA, the agency developed a "Unified Visual Communications System." The successful application of this system was recognized in 1985, when NASA received the prestigious "Award for Design Excellence" from President Reagan.

\section{Fine Arts}

NASA's Fine Arts program commissions artists to document and depict significant NASA activities, events, and accomplishments through various media. These original works are displayed for public viewing at major NASA Visitor Centers. Most recently, a musician 
was commissioned to portray the glory and pride of our country's return to space with the launch and landing of STS-26 (the Discovery mission) in 1988.

\section{Artifacts}

This program oversees the identification and disposition of NASA artifacts. If NASA determines that an artifact is no longer useful either technically or for exhibition purposes, then the artifact is, in most cases, transferred to the Smithsonian Institution's National Air and Space Museum for public display.

\section{Guest Operations}

Guest Operations is responsible for planning and managing an efficient and cost-effective operation for accommodating the public at Space Shuttle launches and landings. Guest invitations and protocol activities associated with certain special and public events conducted jointly by NASA and other organizations, both domestic and foreign, are also coordinated.

\section{Public Inquiries}

The vast majority of all NASA Headquarters public mail is screened and answered by NASA Public Services. Currently, this office is responding to approximately 25,000 pieces of correspondence annually.

\section{Speaker Services}

As a service to NASA public speakers and other recognized speakers outside the agency, NASA maintains and distributes a "Speaker Reference Book" on current NASA programs and activities, as well as significant speeches, congressional testimony, etc., delivered by the NASA Administrator and other senior agency officials.

\section{EMPLOYEE COMMUNICATION}

In the wake of the Challenger accident in 1986, NASA began to see the need for an intensified and more timely form of internal communication programs for its employees. All that existed was an agency-wide monthly publication and a variety of biweekly or monthly newsletters generated at individual installations.

In an agency-wide survey at that time, NASA employees indicated they generally received their news about NASA from their daily newspapers or local or national television news programs. Erroneous, controversial, or confusing media reports about the agency often angered and confused employees. Morale at the agency became a serious problem.

To help correct this problem, an Internal Communications Office was established within the Office of Management to develop a program of information specifically aimed at the employee and quickly delivered. The new internal communications system was patterned after NASA's successful public and news-media information activities. It is believed to be unique among government agencies, but is essential in high-visibility organizations such as NASA where employees must be kept fully aware of significant events that will attract public attention. Such awareness keeps morale up and effectiveness high.

Televised information programs, collectively called NASA Update, were transmitted over 
the NASA satellite transponder to all agency facilities throughout the United States. NASA management, including the Administrator and astronauts, reported on Shuttle recovery progress and agency officials were asked to discuss new programs and the status of ongoing projects. Even members of the media, former members of Congress, and nationally recognized scientists and engineers appeared to discuss their views of the agency's recovery from the loss of Challenger and the impact of the Presidential Commission findings.

As the Internal Communications Branch began to take shape, it became evident that gathering of news and information even for employees was the responsibility of experienced public affairs specialists. The Internal Communications Office was transferred to the newly established Office of Communications. Under this office several new or revised information projects, specifically for NASA employees, were begun.

\section{Information Efforts for Employees}

\section{NASA Headline News}

NASA Headline News is a daily news report written and edited by the Internal Communications Branch. Headline News uses a 120-second, 1-page news format which usually fills a single $8 " \times 11$ " page and takes about 2 minutes to read. The information is gathered from NASA news releases, wire services, major newspapers, television news services, aerospace-related publications, and other independent news sources. The daily news report also contains the schedule of televised public affairs events available for viewing on the NASA satellite transponder. Headline News is filed daily, Monday through Friday at 12:00 pm Eastern time, on the NASAmail (GTE Telemail) electronic bulletin board. Agency employees and contractors who have access to the NASAmail system may avail themselves of the information. In addition, the news report is recorded on a digital voice repeater that may be dialled at 202/755-1788. Since its inception, aerospace media also avail themselves of this service because of its immediacy and brevity.

\section{Daily News in Brief}

Daily News in Brief is a summary of major news stories about NASA filed in major newspapers and aerospace publications, and broadcast on radio and television. Daily News in Brief is the most popular of the internal communications information publications. Each day an editor reads a wide variety of information sources and abstracts the most important articles. Even if information is found to be incorrect or negative to the agency it is summarized and filed. Gross errors found in the stories are generally noted by the editor and corrected if warranted. This procedure assures that NASA management and employees are aware of any negative or erroneous information about the agency. Daily News in Brief is filed at 12:00 pm each weekday on the NASAmail electronic service.

\section{NASA Update}

The initial biweekly televised discussion programs with agency and agency-related individuals underwent a major format change after its first year and emerged as a weekly 5-minute NASA news program. It is a fast-paced program of the latest agency news and it also presents a variety of video-taped features provided by NASA installations. The show 
is produced in Washington, D.C., and relayed to other NASA installations every Thursday via the NASA satellite transponder. Installations tape the program and play it over their internal cable systems that day and again on Friday. The program is also shown on monitors located in agency credit unions, employee stores, hallways, and cafeterias. Because the program is transmitted by satellite transponder, non-NASA organizations can view the program as well.

\section{NASA Activities}

NASA Activities, the agency-wide employee publication, recently underwent a major format change. Higher quality newsprint, liberal use of photographs, and a variety of interesting features have improved its acceptance by employees. The editor works closely with his peers at the installations in an effort to showcase important center activities for readers. With a distribution of 35,000, the 16-page publication is sent to every civil service employee in NASA. Additional copies are sent to major NASA contractors and retirees, and may be purchased by the general public through the Government Printing Office.

\section{Current News}

Current News is an expanded version of a previously existing daily media reprint effort of the NASA newsroom. Current News is a limited-distribution compilation of major newspaper, wire service, and trade magazine articles and summaries of television news reports. Every morning the Newsroom clips up to 10 major newspapers and some trade papers. Same-day distribution is made to major program offices in Headquarters, selected congressional offices, and several offices serving the White House. Current News is also distributed to macro program and project offices throughout the agency.

\section{Television Services}

Another effort at NASA Headquarters is the production of special television and videotaped programs.

An offshoot of the regular television production efforts is special televised programs aimed specifically at NASA employees. The Internal Communications Branch produces special programs or assists in the production of special messages to employees by the Administrator or other management personnel.

In addition, NASA has produced a 12-minute "Welcome to NASA" video-tape that is shown to new employees. Also in production is a special 15-minute tape explaining the rudiments of the agency's proposed drug-testing program.

\section{Installations Augment Headquarters Output}

At NASA Headquarters and most of the installations, additional efforts are made to keep employees better informed. At Headquarters a biweekly bulletin board called HEADS UP is posted at all elevators in the major buildings occupied by the agency. HEADS UP features a variety of institutional news items that are of local interest only.

Installations expanded or improved their own methods of distributing information by combining the Headquarters-produced information sent by electronic mail with their own. Therefore, each installation is able to augment the agency-wide news with local information. 


\section{WORLDWIDE ELECTRONIC MAIL NETWORK}

NASA's space efforts have worldwide interest and participation. NASAmail (a GTE Telemail system) is used extensively not only by NASA employees, but also by its contractors, to communicate among scientists, engineers, and professional and administrative personnel. NASAmail is the lifeblood of many projects that have international participants. The network literally stretches around the world. It also finds its way into scores of colleges and universities throughout the United States and Canada.

The NASAmail system affords NASA a vehicle to distribute its information. NASA Headline News and Daily News in Brief are read not only by NASA employees and contractors in Australia, Asia, and Europe, but also by foreign space scientists and engineers.

Further distribution of the news headline service and TV schedule occurs through NASA SPACELINK, the agency's electronic information system for the educational community. The computer-accessed services, provided by NASA's educational affairs activities and operated by the Marshall Space Flight Center's Public Services and Education Branch, includes Headline News as part of its service to teachers and students.

\section{THE FUTURE}

As the worldwide information explosion grows, particularly in scientific and technical areas, NASA is continually faced with providing greater and greater amount of information to the outside world. Therefore, it is increasingly important that information be distributed not only quickly and efficiently, but in a cost-effective manner.

As new technologies in information dissemination develop, they are looked at by the Office of Communications. Although no special office has been established to track new technologies, several employees are instrumental in evaluating and implementing new communications techniques.

One NASA program that will require special efforts is the information flow from the Hubble Space Telescope. The orbital observatory, scheduled to be launched in March 1990, is expected to create an avalanche of written and pictorial information in the field of astronomy. Other programs such as the Galileo mission to Jupiter and the mapping of Venus by the Magellan spacecraft also present a challenge to NASA's information efforts.

Farther down the road, but of extreme concern now, is the flow of information expected from Space Station Freedom. Once in orbit, the station will provide information not only to the United States but to a variety of international partners. Television will play a major part in passing along scientific and technical information.

\section{CAN NASA MEET THE CHALLENGE?}

As the agency plans for a return to the Moon, about the year 2000, and eventual manned exploration of Mars, communications to the scientific community and the public present a challenge of unprecedented proportions. Space missions will become more complex technically, scientifically, and administratively. NASA has been cooperating with foreign governments in a variety of international space projects over the past three decades, and such efforts are on the increase.

The public information program of NASA's Office of Communications has been highly 
successful for the past 30 years. It will require continual upgrading in the years ahead. Through the use of new and improved communications methods and innovative planning, NASA will be able to keep the world abreast of new and exciting breakthroughs in space science and applications. 